- [a] one-sided and biased map". A map that appeared in a review of Chinese demography published in Science ${ }^{3}$ provoked similar criticism. Science responded with an Editor's Note $^{4}$ stating that the journal "does not have a position with regard to jurisdictional claims" but that it is "reviewing our map acceptance procedures to ensure that in the future Science does not appear to endorse or take a position on territorial/jurisdictional disputes".

Meanwhile, Michael Oppenheimer, a geoscientist at Princeton University, New Jersey, who is co-editor of Climatic Change, has received a barrage of e-mails since June from scientists contesting a Chinese map that his journal published more than four years ago ${ }^{5}$. The map includes a thick 'cow-tongue' shaped dotted line that claims for China a wide swathe of the South China Sea, reaching down towards Malaysian Borneo. The scientists, from Vietnam, Finland, Canada and elsewhere, are demanding a correction to the map. But this kind of highly politicized debate over territory "is not a question that a journal like ours wants to deal with", says Oppenheimer.

Other Vietnamese scientists contacted by Nature were most angered by instances of what they consider to be gratuitous uses of the

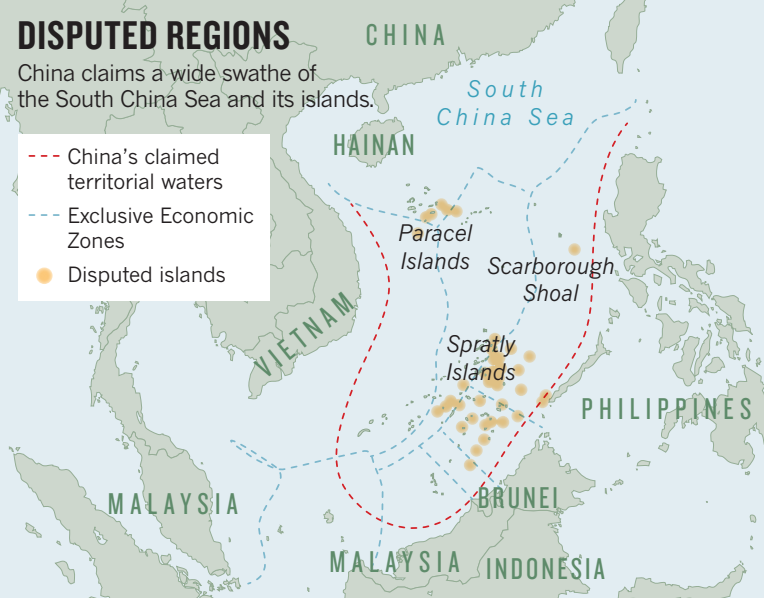

chance to correct or amend the figure. Shao declined, explaining in an e-mail that the figure "is requested by the Chinese government".

Jingyun Fang, a climate-change specialist at Peking University in Beijing who was a co-author on the Nature review, says that he included the insert because "we should follow China's law to include these Chinese seas in the map". Neither Fang, Shao nor any of four authors of other articles that included similar maps responded to requests from Nature for details of these regulations.

Science, Nature and Climatic Change have ultimately decided not to remove the offending maps.

cow-tongue map. "They include the line around the South China Sea even when this region, and the islands within it, have absolutely zero relevance to the topic," says Q. Tuan Pham, a chemical engineer at the University of New South Wales in Sydney, Australia.

Why Chinese scientists include the controversial map in their papers is not clear. Following the e-mails, Oppenheimer decided that the disputed map had no relevance to the conclusion of the paper in question, but he contacted the lead author, Xuemei Shao of the Institute of Geographic Sciences and Natural Resources Research in Beijing, to offer him the
But Tuan Nguyen, a professor of medicine at the Garvan Institute of Medical Research in Sydney, who has independently complained to journal editors about China's maps of the South China Sea, says that maps in journals should be treated as scientific data and verified before publication. "The publication of such a map represents an abuse of science," he says. $\square$ SEE EDITORIAL P.285

1. Nature 476, 10-11 (2011).

2. Piao, S. et al. Nature 467, 43-51 (2010).

3. Peng, X. Science 333, 581-587 (2011).

4. Bradford, M. Science 333, 1824 (2011).

5. Liang, E. et al. Climatic Change 79, 403-432 (2006).

\title{
US row threatens Chinese links
}

\section{Dispute intensifies over a ban on some types of scientific cooperation with China.}

\section{BY EUGENIE SAMUEL REICH}

$\mathrm{W}$ hen US presidential science adviser John Holdren hosted a dinner and meetings between US and Chinese science officials in May, he must have known it would lead to a high-level stand-off. That came to pass on 11 October, when the Government Accountability Office (GAO), an arm of Congress, concluded in a report that those activities violated legislation banning scientific cooperation with China by NASA and by the White House Office of Science and Technology Policy (OSTP), which Holdren directs.

Frank Wolf (Republican, Virginia), the congressman who chairs the subcommittee that funds science agencies including the OSTP and NASA, inserted the ban into a spending bill that was passed last spring. Now, backed by the GAO report, he has asked the US Department of Justice to rein in Holdren's China-related activities; if the department refuses to do so, the matter could end up in the courts.

Holdren - armed with a memo from the justice department saying that he has the right to conduct diplomacy on behalf of US President Barack Obama, even without congressional approval - is showing no signs of backing

"This has
potential to cut
off collaboration
with a country
on a rapidly
rising science
trajectory."
down. Yet sciencepolicy experts say that the dispute has the potential to cast a cloud over joint academic and commercial research efforts between the two economic superpowers. "This has potential to cut off collaboration with a country on a rapidly rising science and technology trajectory," says Richard P. Suttmeier, a retired expert on Chinese science policy based in Keene Valley, New York.

Relations between the United States and
China have their roots in a historic 1972 visit to Beijing by US president Richard Nixon. That led to a 1979 agreement between the two governments for cooperation on scientific activities. Suttmeier estimates that US agencies now have more than 30 agreements on scientific cooperation with their equivalents in the Chinese government. The US National Science Foundation (NSF) opened an office in Beijing in 2006, and the US Department of Energy founded a US\$150-million Clean Energy Research Center with China in 2009. Chinese researchers are now more likely to collaborate and co-author papers with scientists from the United States than with those from any other country.

"I don't understand the motivation for trying to cut off something of benefit to both sides," says Martin Briggs, a hydrogeology graduate student at Syracuse University in New York, who spent two months at Fudan University in Shanghai on a fellowship funded by the NSF to learn about water quality. 
Wolf's spokesman Daniel Scandling says that the congressman sought to ban NASA and the OSTP from fostering relations with China after NASA administrator Charles Bolden visited the country last year and invited Chinese officials to visit NASA facilities in return. "Congressman Wolf is deeply concerned by China's spying and theft of technology and doesn't think it is wise to give the Chinese access to advanced space technologies," Scandling says.

Few existing NASA activities will be curtailed by the ban. But because much of US science relies on the OSTP for high-level coordination, the ban could derail activities by more agencies than Wolf intends to target. He has publicly questioned the wisdom of NSF activities involving China, but Scandling says that Wolf has no immediate plans to block cooperation by other agencies. Wolf's subcommittee has already approved a bill that would extend the ban into the 2012 fiscal year; it is now awaiting passage through the House.
But Mu Rongping, a science-policy analyst at the Chinese Academy of Sciences in Beijing, doesn't expect a major withdrawal from China-US activities by the United States. It is clear that cooperation on funding of projects and mobility of researchers is win-win for both sides, he explains.

"US bilateral activities in the fields of science, technology and innovation policy are important and necessary for both countries, not just for China," he says.

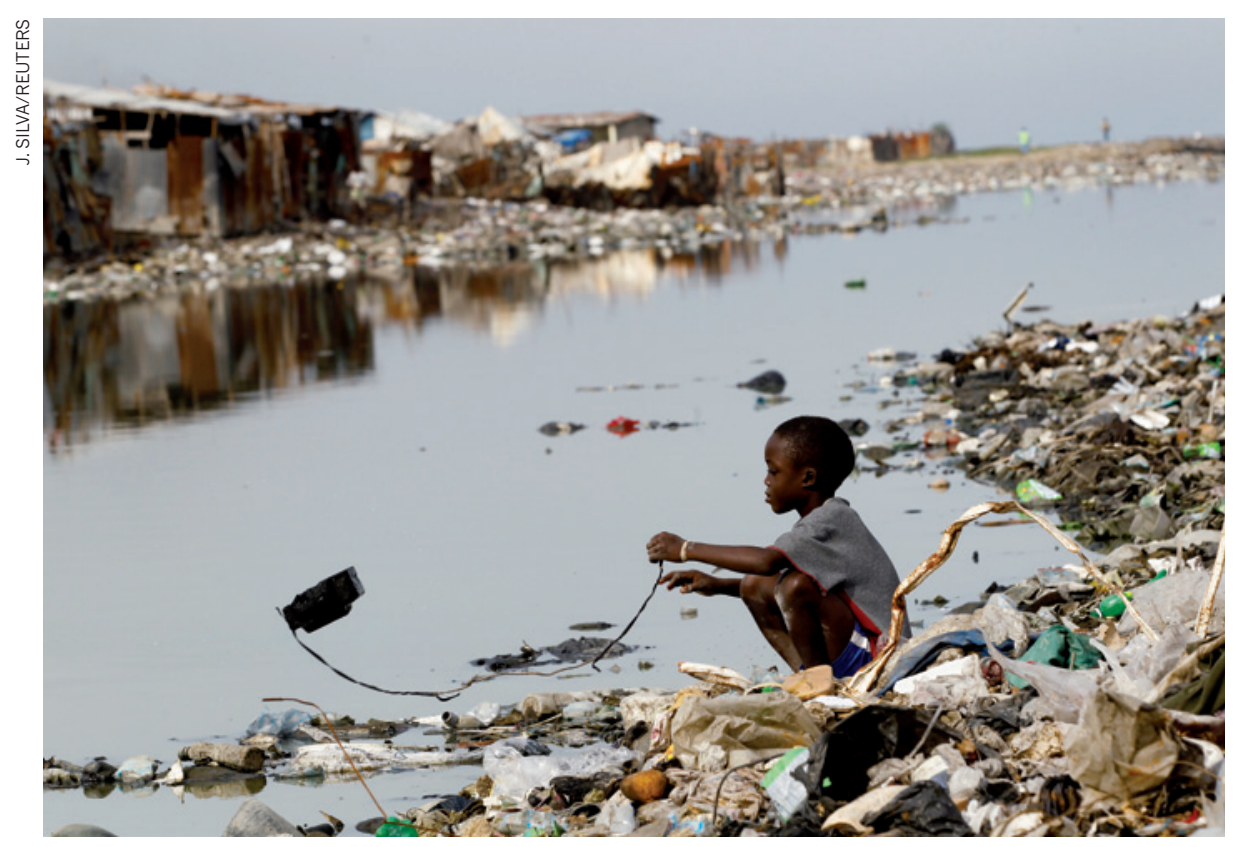

Until clean water and sanitation are readily available in Haiti, cholera outbreaks will continue.

\section{PUBLIC HEALTH}

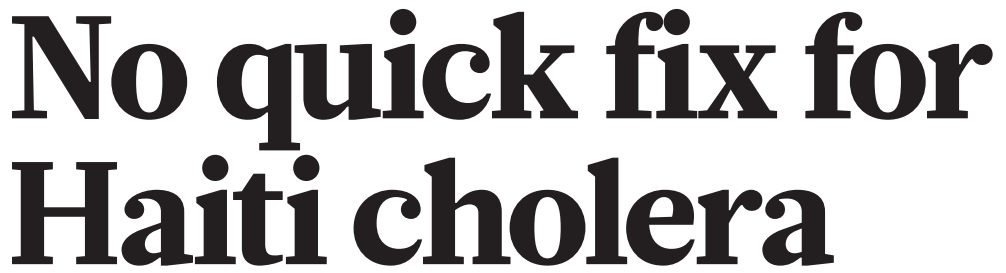

\section{As outbreak enters its second year, relief bodies move to roll out vaccine for the first time.}

\section{BY DECLAN BUTLER}

A year after cholera broke out in the aftermath of the January 2010 Haiti earthquake, the epidemic has disappeared from the headlines, but it continues to wreak a deadly toll. Mortality rates remain high in some areas, but donor funding for front-line response teams is drying up, even as a newly approved vaccine offers a glimmer of hope.

The epidemic has already caused almost half a million cases, half of which have required hospitalization. Haiti's health ministry says that roughly 6,500 people have died from their infections - a figure widely believed to be an underestimate.

The Pan American Health Organization (PAHO) in Washington DC expects the epidemic to ease partially, but nonetheless predicts a further 250,000 cases next year, says Peter Graaff, the PAHO/World Health Organization (WHO) representative in Haiti.

Shanchol, a vaccine approved by the WHO

for worldwide use on 29 September, could brighten the outlook. It was developed by the International Vaccine Institute in Seoul with support from the Bill \& Melinda Gates Foundation, and is produced by Shantha Biotechnics in Hyderabad, India, a subsidiary of vaccine company Sanofi Pasteur. Two groups of nongovernmental organizations (NGOs) operating in Haiti now intend to include the vaccine in their own emergency responses to cholera.

At US\$1.85 a dose, Shanchol is cheaper than the only other currently available cholera vaccine - Dukoral, made by Crucell, based in Leiden, the Netherlands. Shanchol is also given orally, and requires fewer doses in children under six, who are among the most vulnerable to cholera. The vaccine's benefits "are really clear for the outbreak contexts in which MSF works", says Julia Hill, vaccines policy adviser at Médecins Sans Frontières (MSF), also called Doctors Without Borders, in Geneva, Switzerland.

MSF has one of the largest ongoing emergency-response operations in Haiti, treating as many as one-third of all reported cholera cases. It intends to begin vaccinating with Shanchol soon in Haiti; it is also considering a vaccination campaign in West and Central Africa, where cholera is currently resurging. MSF has yet to finalize details of its campaign, but will probably focus vaccination efforts on vulnerable groups, such as people in remote rural areas, who lack timely access to treatments.

Because mountainous communities can often be reached only after half-a-day's journey on foot, "a whole village can be infected before help arrives", says Michel Van Herp, an epidemiologist in the MSF office in Brussels. Van Herp oversaw MSF's field response at the start of the epidemic, when as many as $9 \%$ of cases resulted in fatalities. In the capital, Portau-Prince, that figure has now been brought down below $1 \%$, but in remote rural areas, death rates as high as $5-10 \%$ persist, he says.

A separate campaign aims to vaccinate 100,000 vulnerable Haitians using 200,000 doses of Shanchol. That effort will be carried

\section{DNATURE.COM}

For more, see Haiti: One year of cholera: go.nature.com/zvynyf out jointly by GHESKIO, an NGO based in Portau-Prince, and Partners in Health (PIH), a nonprofit organization 